ojs.uv.es/index.php/qfilologia/index

Rebut: 0I.05.202I. Acceptat: 05.10.202I

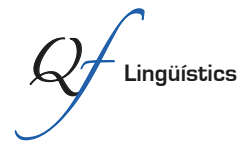

Per a citar aquest article: Meléndez-Labrador, Sandra. 202I. "Autoidentidad y discursos mediáticos de la discapacidad en la prensa deportiva digital". Quaderns de Filologia: Estudis Lingüístics XXVI: I29-I50.

doi: $10.7203 /$ QF.26.2198I

\title{
Autoidentidad y discursos mediáticos de la discapacidad en la prensa deportiva digital
}

\section{Self-identity and media discourses of disability in the digital sports press}

\author{
SANDRA MeLÉndeZ-LabRador ${ }^{\mathrm{I}}$ \\ Universidad del Norte \\ slabrador@uninorte.edu.co
}

Resumen: Esta investigación aborda la relación entre medios y discapacidad desde el área del periodismo deportivo con la cobertura de la prensa digital colombiana de los Juegos Paralímpicos Río 20I6. El estudio analizó los significados asignados por los deportistas paralímpicos colombianos a las noticias publicadas por los medios digitales sobre su participación, así como los elementos de dichas noticias y la manera como influyeron en su autoidentificación mediática. Desde un enfoque crítico-interpretativo, la pesquisa se desarrolló en dos fases: en la primera se realizó un análisis textual de 559 noticias digitales publicadas sobre el tema; en un segundo momento, los datos obtenidos se confrontaron con las y los 45 protagonistas de las noticias a través de entrevistas semiestructuradas. Se constató que la mayoría de las y los atletas carecen de conocimiento y adopción del modelo progresista de representación mediática de la discapacidad, por lo que valoran los discursos mediáticos supercrip con los que son representados como héroes o modelos de inspiración, no por sus logros deportivos, sino por su capacidad de superación "a pesar" de la discapacidad. Se concluye que, en la medida en que los medios digitales los muestran como atletas, especialmente que inspiran a otras personas con y sin discapacidad, incrementan las posibilidades de que estos deportistas desarrollen una autoidentidad mediática. En tal sentido, a partir de la valoración positiva o negativa de determinados elementos de las noticias, los deportistas se sintieron o no autoidentificados mediáticamente de manera impuesta, asumida, negociada o rechazada.

Palabras clave: autoidentidad mediática; medios digitales; discapacidad; discurso mediático; paralímpicos.

Abstract: This research addresses the relationship between media and disability from the area of sports journalism with the Colombian digital press coverage of the Rio 2016 Paralympic Games. The study analyzed the meanings assigned by Colombian Paralympic athletes to the

\footnotetext{
${ }^{\mathrm{I}}$ Cofundadora y directora del Observatorio Latinoamericano de Discapacidad y Comunicación - Obladic www.obladic.org
} 
news published by the digital media about their participation, as well as the elements of such news and the way in which they influenced their media self-identification. From a critical-interpretative approach, the research was developed in two phases: in the first phase, a textual analysis of 559 digital news items published on the subject was carried out; in a second phase, the data obtained were confronted with the 45 protagonists of the news items through semi-structured interviews. It was found that most athletes lack knowledge and adoption of the progressive model of media representation of disability, so they value the "supercrip" media discourses with which they are represented as heroes or models of inspiration, not for their sporting achievements, but for their ability to cope "despite" disability. It is concluded that, to the extent that digital media show them as athletes, especially those who inspire other people with and without disabilities, they increase the chances of these athletes developing a media self-identity. In this sense, based on the positive or negative assessment of certain elements of the news, athletes felt media self-identified in an imposed, assumed, negotiated or rejected way.

Keywords: media self-identity; digital media; disability; media representation; paralympics.

\section{Introducción}

\subsection{La autoidentidad, la discapacidad y la experiencia mediada}

Para Anthony Giddens, el yo se construye reflexiva e interpretativamente y es manifestado por el individuo a manera de biografía. En el proceso en el que el agente construye su proyecto identitario, estructuras sociales como los medios de comunicación lo ciñen, reducen, limitan o también lo motivan a actuar. Al respecto afirma: "se trata de una experiencia mediada que ha influido profundamente en la autoidentidad y en la organización básica de las relaciones sociales" (I996: 37).

Para el autor, la mejor manera de analizar la identidad del yo en la mayoría de instancias es a partir del contraste con individuos cuyo sentido del yo puede estar fracturado. En ese orden, el presente estudio analizó la autoidentidad mediática de individuos con ontología segura (deportistas con discapacidad congénita) y fracturada (con discapacidad adquirida o sin discapacidad). Los primeros han experimentado a lo largo de su vida situaciones de discriminación negativa relacionada con la discapacidad, mientras los segundos experimentaron una ruptura en su biografía al adquirir una discapacidad cerca de o en la adultez y, con ella, las correspondientes situaciones de discriminación negativa de manera abrupta. En esta línea también se ubican los guías de atletas ciegos, quienes pasan de ser deportistas convencionales a paralímpicos. 


\subsection{La discapacidad y el deporte en los medios}

Investigaciones sobre el tema han demostrado una cobertura de los Juegos Paralímpicos (JJ. PP.) menor a la de los Olímpicos en la prensa, por ejemplo, en Brasil y Portugal con respecto a la edición de Pekín 2008 (Figeiredo \& Novais, 20Io); o en la prensa española, donde resultó menor a la de cualquier otro deporte durante los juegos de Londres 2012 (Solves, Sánchez \& Rius, 20I8); o en Omán y Taiwán donde fue nula, mientras que en Arabia Saudí fue mínima (Cheong et al., 2020). En general existe una habitual invisibilidad de los deportes paralímpicos en los medios de comunicación (Hardin, 2008; Rojas-Torrijos \& Ramon, 202I), aun cuando las Paralimpiadas pueden considerarse el tercer evento deportivo mundial más importante después de los Olímpicos y el mundial de fútbol, respectivamente.

Además del reto de garantizar la visibilidad de las personas con discapacidad (en adelante, PCD) por parte de los medios de comunicación, persiste el de asegurar una cobertura objetiva, sin estereotipos ni modelos estigmatizados, como lo declara la Convención por los derechos de las PCD (ONU, 2006). En ese sentido los medios deben ofrecer contenidos diversos y "dar exposición a los deportes, ligas e individuos sub representados y a las organizaciones, incluidas las mujeres deportistas y los atletas con discapacidades" (Kolotouchkina, et. al. 202I: Io). Al mismo tiempo y respondiendo al necesario enfoque de derechos, deben conocer y utilizar la perspectiva progresista de cobertura de la discapacidad basada en los dos modelos de Clogston: I) de derechos civiles y de minoría, que retrata a las PCD como pertenecientes a una comunidad que cuenta con reivindicaciones políticas legítimas y derechos civiles por los que pueden luchar como los demás grupos; 2) de pluralismo cultural, donde la PCD es considerada "un individuo polifacético cuya discapacidad es sólo un aspecto de muchos. No se presta excesiva atención a la discapacidad. El individuo es retratado al igual que otras personas sin discapacidad" (normalización) (I994: 47); 3) y en un tercer modelo aportado por Haller (I995), el legal, en el que los medios explican que es ilegal tratar a las PCD de ciertas maneras, con argumentos legales presentados como herramientas para poner fin a la discriminación.

En contraste, la amplia investigación desarrollada en el área del deporte, los medios y la discapacidad, que en la última década ha crecido exponencialmente ${ }^{2}$, ha ubicado como líder el marco de representación mediática

\footnotetext{
${ }^{2}$ Excepto en Latinoamérica, donde Brasil es el mayor aportante de nuevo conocimiento en esta área.
} 
supercrip, que ha trascendido "hasta convertirse en un elemento central de las publicaciones paralímpicas oficiales y otras de marketing”, valiéndose de las expresiones visuales como factor clave para alimentar la creciente popularidad tanto de los JJ. PP. como de las y los deportistas (McGillivray et al., 202I: 28). Este criticado modelo, como se explicará en la discusión, hace parte de la perspectiva tradicional de representación mediática de Clogston (junto con el modelo médico y el de patología social) y se caracteriza por presentar a las PCD como inválidas, superhumanas o especiales, como héroes discapacitados porque viven una vida normal a pesar de la discapacidad superando la adversidad y sus dificultades (Haller, 2000; Newlands, 20I2). Este famoso marco las muestra "como valientes por superar su discapacidad y por tener éxito en la competición a pesar de sus «incapacidades» para funcionar como un atleta «normal»" (Lindemann \& Cherney, 2008: 352), y es abordado desde una doctrina denominada capacitismo, que otorga valor a la corporeidad estándar en la cual los deportistas convencionales (cuerpos capaces) se definen a partir de su "superioridad" frente al otro (cuerpos con discapacidad o diversidad funcional), por ejemplo las olimpiadas versus las paralimpiadas.

\subsection{Cómo cubrir los Juegos Paralímpicos de Río 2016}

Una manera de garantizar esa cobertura objetiva es a partir de guías como la de IPC (20I4), EFDS (20I6) y Pappous y Souza (20I6). Esta última fue entregada a medios brasileros en los JJ. PP. de Rio con el apoyo del Comité Paralímpico Brasileño, para promover una imagen más inclusiva de las PCD, y es la única publicación basada en investigaciones sobre medios, deporte y discapacidad.

A continuación se exponen las características de lo que Pappus \& Souza (20I6) consideran en su guía como tratamiento inadecuado de información sobre deportistas con discapacidad física y visual 3 : a) presentarles en un contexto de tragedia y fragilidad; $b$ ) presentar a los grupos de atletas como ciegos, amputados o discapacitados; $c$ ) dar prioridad a las limitaciones más que a los hechos deportivos; $d$ ) presentar al o a la atleta como alguien discapacitado/a; e) presentar al o a la deportista con discapacidad física como lisiado/a, paralítico/a, inválido/a, minusválido/a o tullido/a; f) presentar a la o al atleta con

\footnotetext{
3 Tipos de discapacitades con que clasificaron los deportistas paralímpicos colombianos entrevistados para este estudio.
} 
movilidad reducida como coja/o o mocha/o; g) presentar al o a la atleta con amputación como mutilado/a; $h$ ) mostrar al o a la atleta con discapacidad congénita como deforme; i) presentar a un o una atleta de talla baja como enano/a; $j$ ) presentar a una o un atleta con discapacidad visual como ciega/o, cieguita/o, invidente o semividente; $k$ ) representar a una o un atleta con epilepsia como epiléptico/a; l) hablar de sufrimiento, padecimiento, aflicción o defecto de nacimiento cuando se trata la discapacidad; $m$ ) presentar a un o una atleta usuaria de silla de ruedas como preso/a o confinado/a a esta.

Asimismo, la guía señala las condiciones para las expresiones visuales inadecuadas: el o la atleta paralímpico/a aparece en pose pasiva, fuera del campo de competición, sin uniforme/ropa deportiva, en condición de aislamiento y/o tristeza, sin rostro o reflejando expresiones no compatibles con la competición, en ángulo picado, y/o se resalta la discapacidad y/o la falla. Un ejemplo de retrato que promueve el empoderamiento de las y los atletas paralímpicas/ os y su "espíritu atlético", es decir, que cumple con un tratamiento adecuado según los autores se presenta en la figura I.

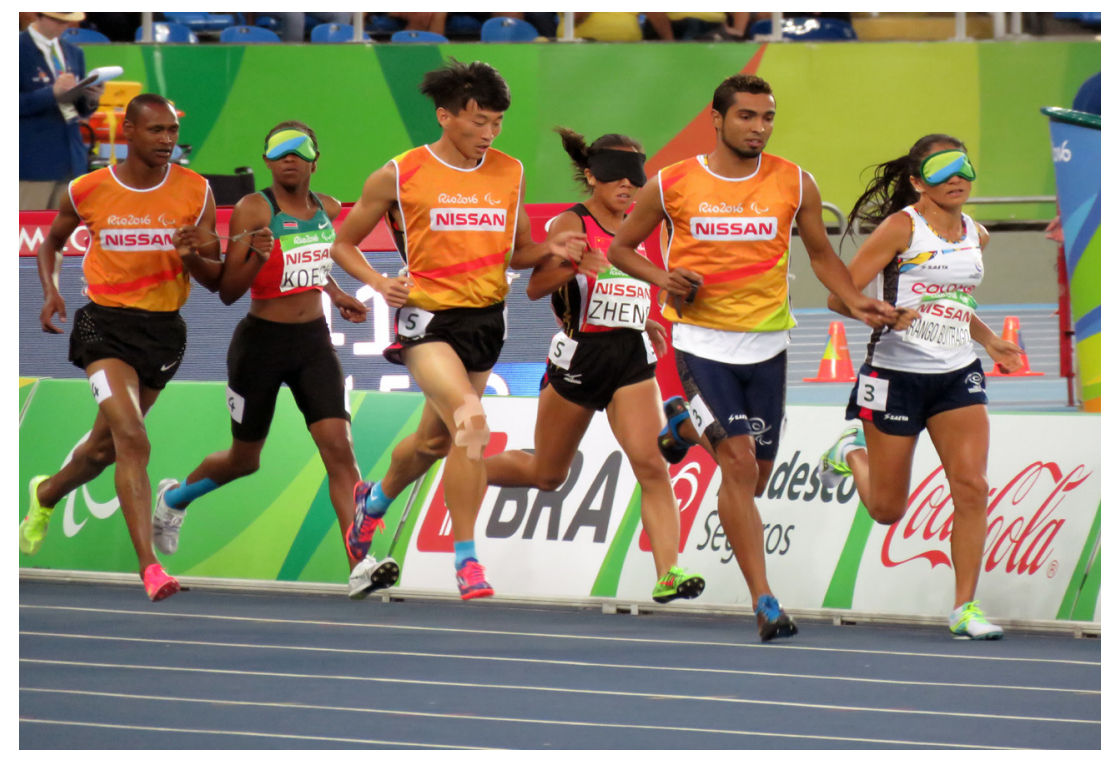

Figura I. Maritza Arango (derecha) y Jonathan Sánchez (guía) en la prueba final I500 metros mujeres Tiı en Río.

Aun conociendo los diversos marcos adecuados e inadecuados de tratamiento de información sobre las PCD, se desconoce si ellas se sienten identi- 
ficadas con alguno cuando son protagonistas de la noticia, y por qué. En razón de ello, se buscó identificar I) el significado que tienen para las y los atletas paralímpicas/os los textos de las noticias que protagonizaron en la prensa digital durante los JJ. PP. de Río 20ı6; y 2) los elementos de tales noticias que influyeron (y por qué) en su autoidentificación mediática.

Para lograrlo, el presente estudio se basó en las negociaciones de identidad planteadas por Pavlenko \& Blackledge (2004), entendidas como procesos de asignación, apropiación y redefinición de la identidad que se dan en la relación intercultural de identidades minoritarias con las mayoritarias, en este caso, de PCD (materia de la noticia) en relación con entes "sin discapacidad" (medios y periodistas productores de la noticia) que pueden llegar a ser discapacitantes, ya que esta diferencia, enmarcada en la discapacidad, fue comprendida desde la definición que hace la Convención sobre los derechos de las personas con discapacidad:

la discapacidad es un concepto que evoluciona y que resulta de la interacción entre las personas con deficiencias y las barreras debidas a la actitud y al entorno que evitan su participación plena y efectiva en la sociedad, en igualdad de condiciones con las demás (ONU, 2006: I).

Estas identidades pueden ser de tres tipos, que Uribe-Jongbloed \& Sarmiento ilustran claramente así:

a) impuesta, cuando la identidad ha sido definida por la mayoría sobre la minoría y surge de un interés de control o dominación (asignación racial colonial, por ejemplo); asumida, cuando una identidad otorgada por la mayoría es usada por la minoría para agruparse como iguales en su diferencia [...] y buscar oposición a las visiones hegemónicas que les son impuestas (el caso de la re significación del concepto niche en Colombia, o el movimiento indígena en Latinoamérica); y negociada, en aquellos casos que la minoría construye y redefine su identidad, evita plantearla en oposición a la mayoritaria y la determina de manera propia (20I4: I70).

\section{Metodología}

Desde un enfoque crítico-interpretativo, la pesquisa se desarrolló en dos fases: en un primer momento se recopilaron datos a partir de un análisis textual, los cuales fueron utilizados en la siguiente fase en entrevistas en profundidad. A partir de 40 alertas de Google programadas con los nombres de las y los 
deportistas se seleccionaron las noticias que llegaron al correo como alertas publicadas entre el 5 y el 20 de septiembre de 2016 en medios colombianos digitales, incluida la prensa nacional de referencia, con el objetivo de analizar la manera como estos cubrieron la participación de la delegación colombiana en los Juegos Paralímpicos de Río. En total se analizaron los textos y fotografías de 559 noticias digitales a la luz de la guía de Pappous \& Souza (20I6), como se explicará más adelante.

En un segundo momento, los datos obtenidos en el análisis textual permitieron seleccionar una o dos noticias con más elementos de tratamiento inadecuado y, a partir de la experiencia de la investigadora como fotógrafa in situ de esos Juegos Paralímpicos, diseñar una noticia con tratamiento adecuado, con el fin de confrontarlas con sus protagonistas a través de entrevistas en profundidad semiestructuradas realizadas a las y los deportistas y sus guías en sus lugares de entrenamiento en 8 ciudades (ver tabla I). Estas noticias actuaron como disparador de emociones al ser leídas y saber que están publicadas en la web. Sobre esto último, las teorías funcionales de la emoción aplicadas al consumo de medios de comunicación abordan las emociones específicas que son activadas por las características de una noticia (por ejemplo, el marco de la historia) y que desencadenan un conjunto de respuestas fisiológicas, perceptivas y conductuales que permiten al individuo enfrentarse rápidamente a los problemas u oportunidades que encuentra en el entorno (Kühne \& Schemer, 20I5). En este caso, las respuestas analizadas fueron del segundo tipo, manifestadas verbalmente. 


\begin{tabular}{|c|c|c|c|c|c|c|c|c|c|c|c|c|c|c|c|c|}
\hline 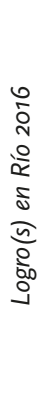 & 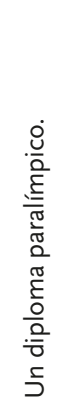 & 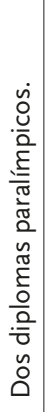 & 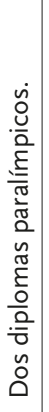 & & 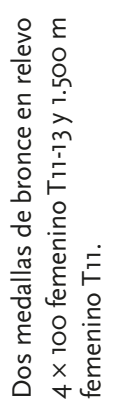 & 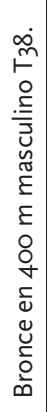 & 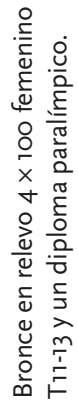 & & 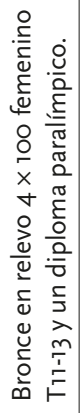 & & & 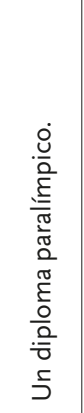 & & 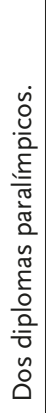 & 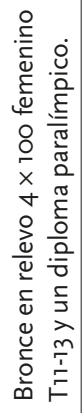 & 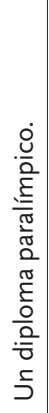 \\
\hline$\frac{\tilde{c}}{\frac{\tilde{Q}}{\Sigma}}$ & 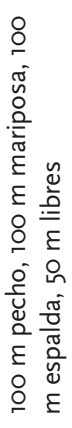 & $\begin{array}{l}\frac{\pi}{0} \\
\frac{0}{\pi} \\
\frac{0}{0} \\
0 \\
\varepsilon \\
0 \\
0\end{array}$ & 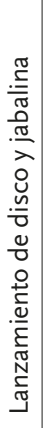 & 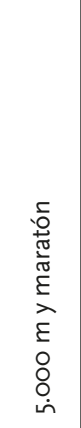 & 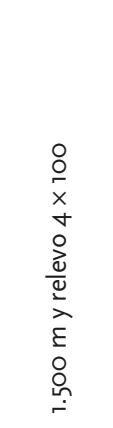 & 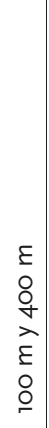 & 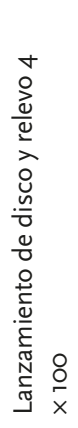 & 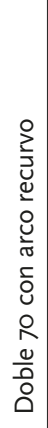 & 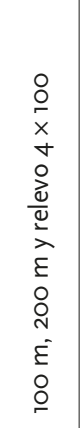 & 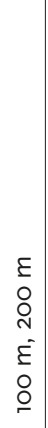 & 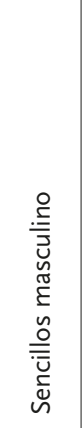 & 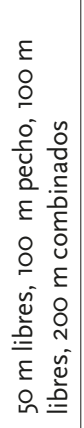 & 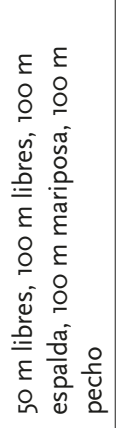 & 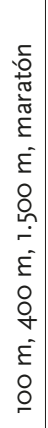 & 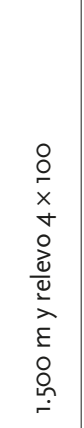 & 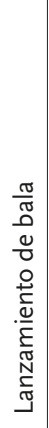 \\
\hline 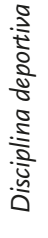 & 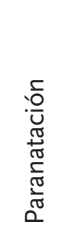 & 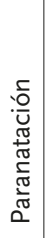 & 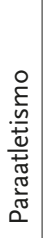 & 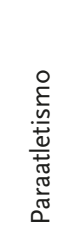 & 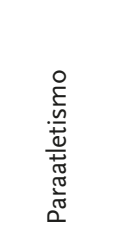 & 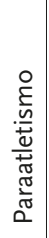 & 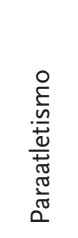 & 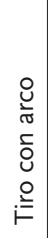 & 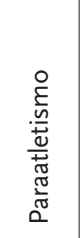 & 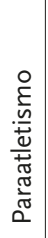 & 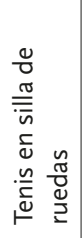 & 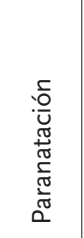 & 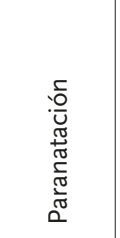 & 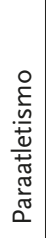 & 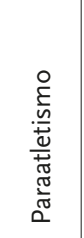 & 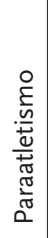 \\
\hline 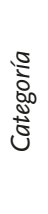 & 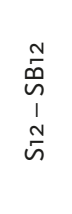 & $\bar{n}$ & 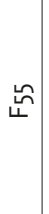 & $\stackrel{N}{F}$ & $\frac{\stackrel{m}{F}}{\stackrel{⿱}{E}}$ & $\stackrel{\infty}{\sim}$ & $\begin{array}{l}F \\
F \\
1 \\
E \\
\bar{E}\end{array}$ & $\frac{\pi}{z}$ & $\Xi$ & $\stackrel{N}{\vdash}$ & $\frac{\mathbb{}}{z}$ & $\begin{array}{l}\sum_{n}^{E} \\
1 \\
1 \\
5 \\
0 \\
1 \\
5 \\
\bar{n}\end{array}$ & 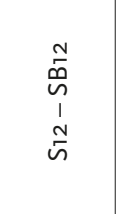 & $\stackrel{\sim}{\sim}$ & $\stackrel{N}{F}$ & $\stackrel{\sim}{\sim}$ \\
\hline$\frac{\Phi}{\frac{\Delta}{+}}$ & 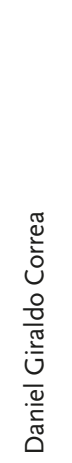 & 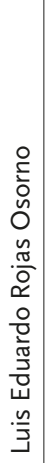 & 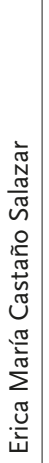 & 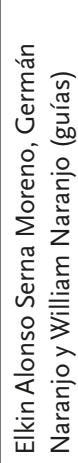 & 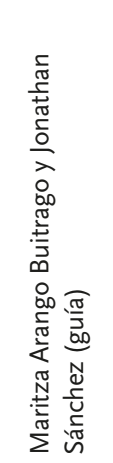 & 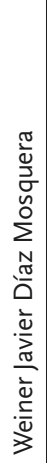 & 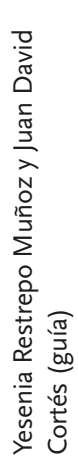 & 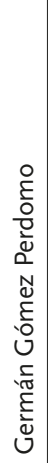 & 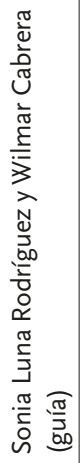 & 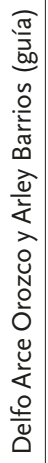 & 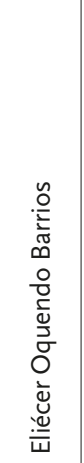 & 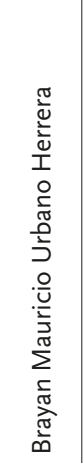 & 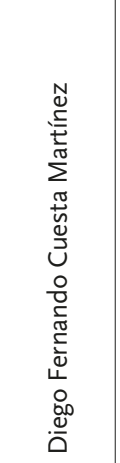 & 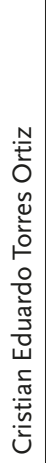 & 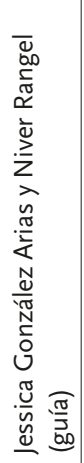 & 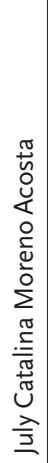 \\
\hline
\end{tabular}




\begin{tabular}{|c|c|c|c|c|c|c|c|c|c|c|c|c|c|}
\hline 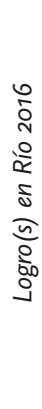 & 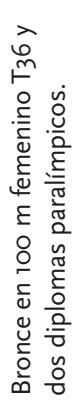 & 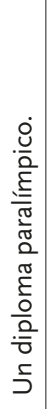 & 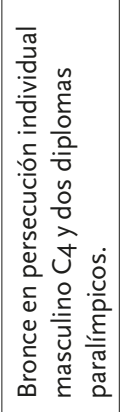 & 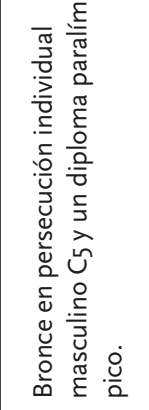 & 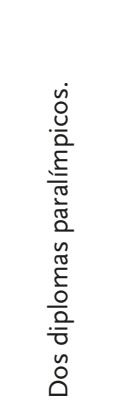 & 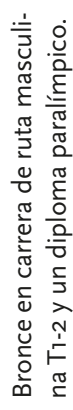 & 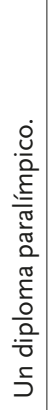 & 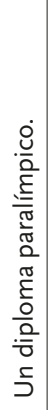 & & 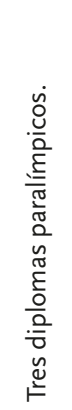 & 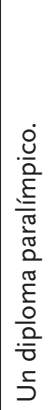 & 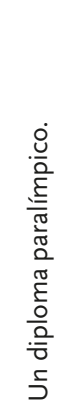 & \\
\hline 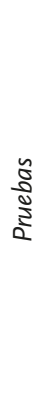 & 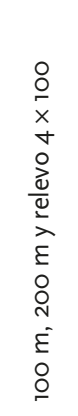 & 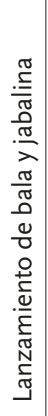 & 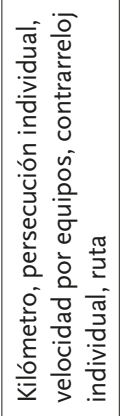 & 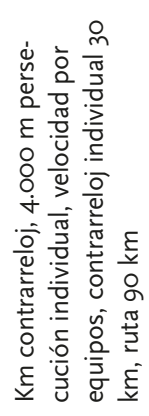 & 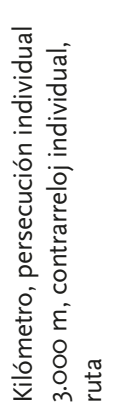 & 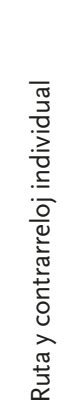 & 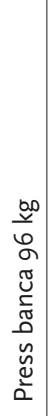 & 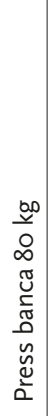 & 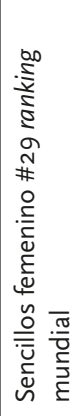 & 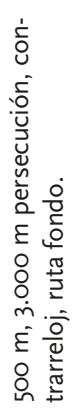 & 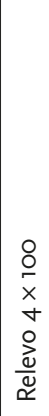 & 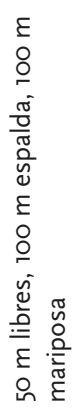 & 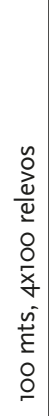 \\
\hline 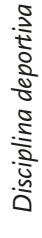 & 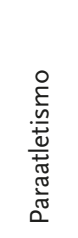 & 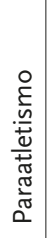 & 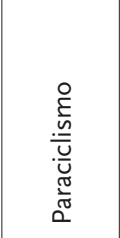 & 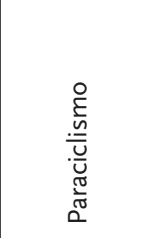 & 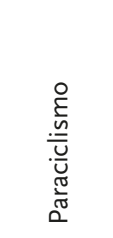 & 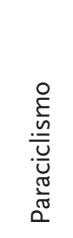 & 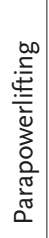 & 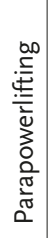 & 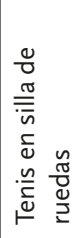 & 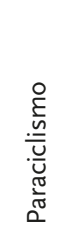 & 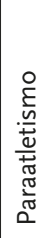 & 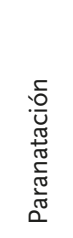 & 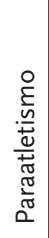 \\
\hline 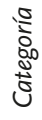 & $\stackrel{\stackrel{m}{r}}{=}$ & 忘 & U & $\stackrel{\sim}{\cup}$ & $\stackrel{\sim}{v}$ & $\stackrel{N}{\vdash}$ & $\frac{\pi}{z}$ & $\frac{\pi}{z}$ & $\frac{\varangle}{z}$ & $\mathcal{U}$ & $\frac{\stackrel{\infty}{m}}{\stackrel{\stackrel{m}{m}}{\mapsto}}$ & $\bar{n}$ & $\hat{m}$ \\
\hline 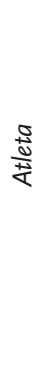 & 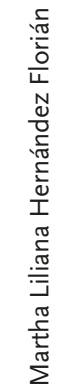 & 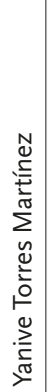 & 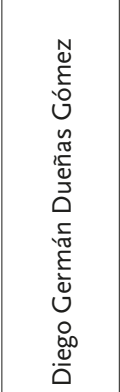 & 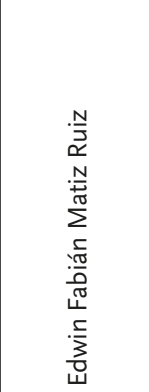 & 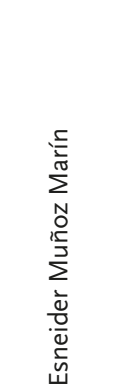 & 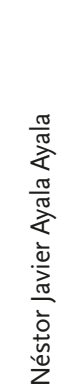 & 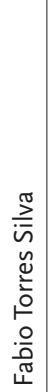 & 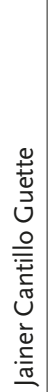 & 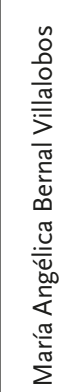 & 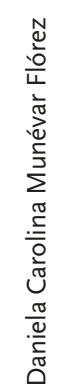 & 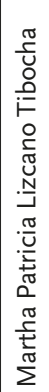 & 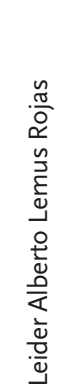 & 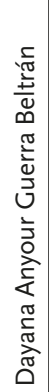 \\
\hline
\end{tabular}




\begin{tabular}{|c|c|c|c|c|c|c|c|c|c|c|}
\hline 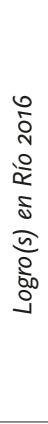 & 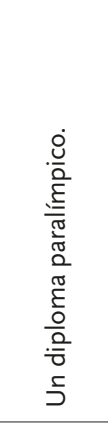 & 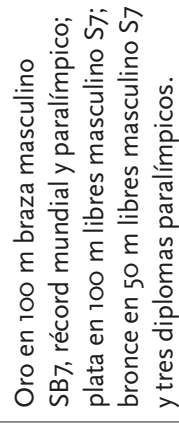 & 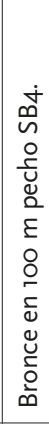 & 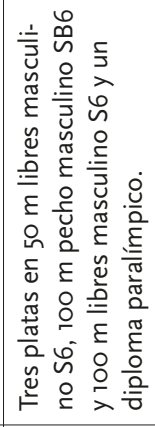 & 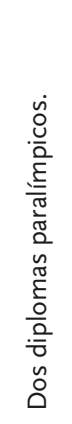 & 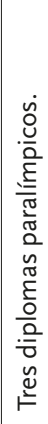 & 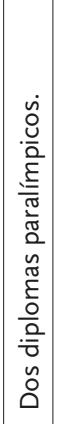 & 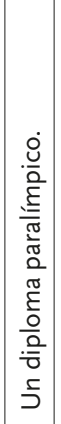 & 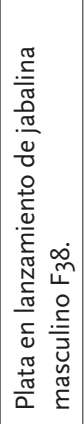 & 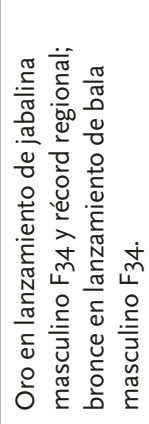 \\
\hline $\begin{array}{l}\tilde{\tilde{s}} \\
\frac{\tilde{\omega}}{\Sigma} \\
\underline{a}\end{array}$ & 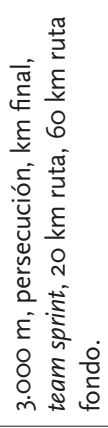 & 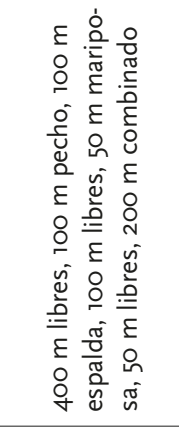 & 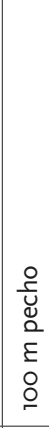 & 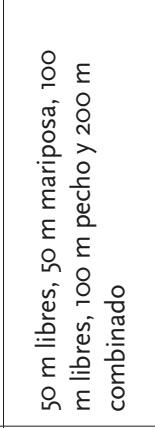 & 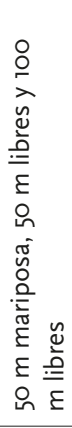 & 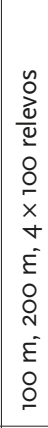 & 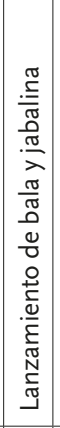 & 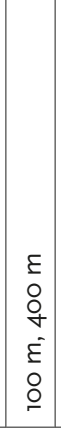 & 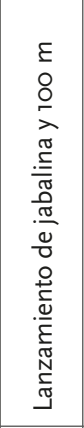 & 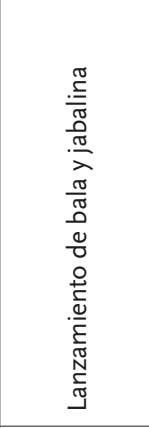 \\
\hline 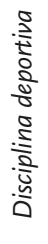 & 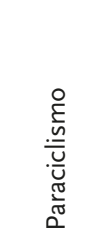 & 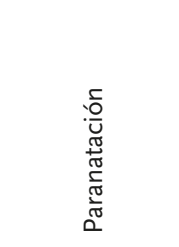 & 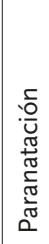 & 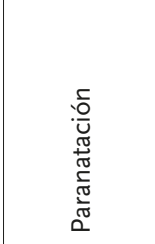 & 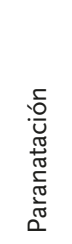 & 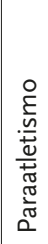 & 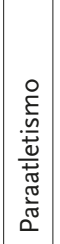 & 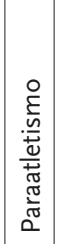 & 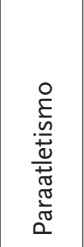 & 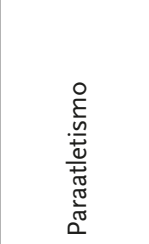 \\
\hline 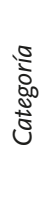 & $\tilde{U}$ & $\begin{array}{l}\sum_{n}^{n} \\
1 \\
1 \\
\hat{n} \\
n \\
1 \\
n\end{array}$ & ڤે & $\begin{array}{l}0 \\
\sum_{n} \\
1 \\
0 \\
0 \\
w 1 \\
1 \\
0\end{array}$ & $\begin{array}{l}0 \\
\sum_{n} \\
1 \\
0 \\
0 \\
w \\
1 \\
0 \\
0\end{array}$ & $\stackrel{\leftrightarrow}{\sim}$ & $\stackrel{\stackrel{\sim}{m}}{.}$ & & $\stackrel{\infty}{\models}$ & $\stackrel{+}{m}$ \\
\hline$\frac{\text { d }}{\frac{D}{+}}$ & 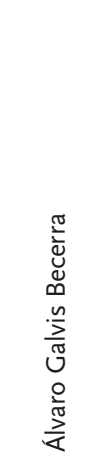 & 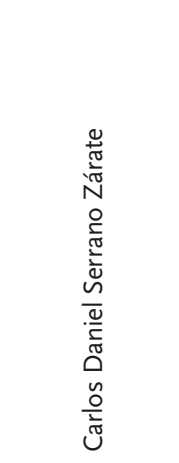 & 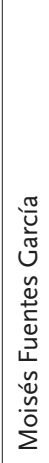 & 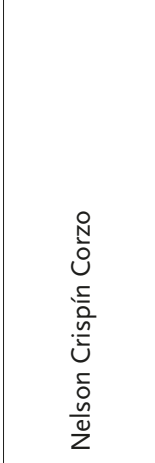 & 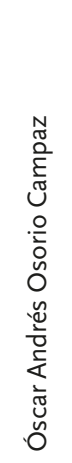 & 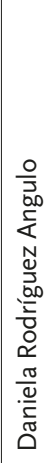 & 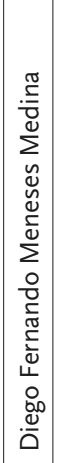 & 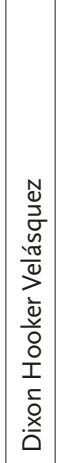 & 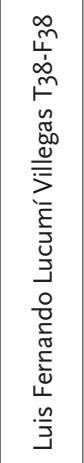 & 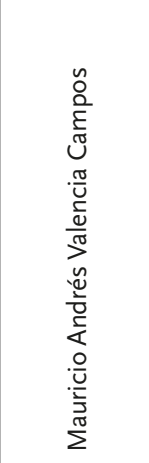 \\
\hline
\end{tabular}




\section{Hallazgos}

El estudio analizó los significados asignados por las y los atletas paralímpicas/ os a las noticias publicadas por los medios digitales sobre su participación. De esta manera, las emociones verbalizadas permitieron valoraciones positivas o negativas de los elementos de las noticias que fueron caracterizadas inicialmente como autoidentidad mediática impuesta (AMI), asumida (AMA), negociada (AMN), sumadas a la identidad rechazada (AMR) y la no mediática o latente (ANMoL) que surgieron tras el análisis de los datos. Estas valoraciones se dieron también en relación con su ontología fracturada y/o segura, y su postura activa o inactiva frente a lo que los medios de comunicación dicen de ellos y la manera como lo dicen. Ver tabla 2.

\begin{tabular}{|l|l|l|l|l|l|}
\hline \multicolumn{1}{|c|}{ Categorías } & \multicolumn{1}{|c|}{ AMI } & \multicolumn{1}{c|}{ AMA } & \multicolumn{1}{c|}{ AMN } & \multicolumn{1}{c|}{ AMR } & \multicolumn{1}{c|}{ ANMoL } \\
\hline $\begin{array}{l}\text { Imágenes } \\
\text { natural e in- } \\
\text { consciente de } \\
\text { las y los atletas } \\
\text { paralímpicas/os } \\
\text { hecha a partir de } \\
\text { otros de manera } \\
\text { inadecuada en } \\
\text { los medios. }\end{array}$ & $\begin{array}{l}\text { Autodefinición } \\
\text { consciente de } \\
\text { las y los atletas } \\
\text { paralímpicas/os } \\
\text { hecha a partir de } \\
\text { otros en los me- } \\
\text { dios como una } \\
\text { cosmovisión } \\
\text { hegemónica'. }\end{array}$ & $\begin{array}{l}\text { Autodefinición } \\
\text { consciente de } \\
\text { las y los atletas } \\
\text { paralímpicas/ } \\
\text { os hecha a partir } \\
\text { de otros en los } \\
\text { medios, y rede- } \\
\text { finida por ellos } \\
\text { mismos. }\end{array}$ & $\begin{array}{l}\text { Abandono de } \\
\text { una autodefi- } \\
\text { nición de las y } \\
\text { los atletas pa- } \\
\text { ralímpicas/os } \\
\text { hecha a partir } \\
\text { de otros en los } \\
\text { medios. }\end{array}$ & $\begin{array}{l}\text { No existe au- } \\
\text { todefinición a } \\
\text { partir de otros } \\
\text { ni de ellos } \\
\text { mismos en los } \\
\text { medios. }\end{array}$ \\
\hline $\begin{array}{l}\text { Valoración } \\
\text { positiva (gozo, } \\
\text { complacencia) }\end{array}$ & $\begin{array}{l}\text { Tratamiento } \\
\text { inadecuado }\end{array}$ & $\begin{array}{l}\text { Tratamiento } \\
\text { inadecuado } \\
\text { Tratamiento } \\
\text { adecuado }\end{array}$ & $\begin{array}{l}\text { Tratamiento } \\
\text { adecuado }\end{array}$ & No & No \\
\hline $\begin{array}{l}\text { Valoración } \\
\text { negativa (ira, } \\
\text { disgusto, } \\
\text { tristeza) }\end{array}$ & No & $\begin{array}{l}\text { Tratamiento } \\
\text { inadecuado }\end{array}$ & $\begin{array}{l}\text { Tratamiento } \\
\text { inadecuado }\end{array}$ & $\begin{array}{l}\text { Tratamiento } \\
\text { inadecuado }\end{array}$ & No \\
\hline Rol & Inconsciente & $\begin{array}{l}\text { Pasivo cons- } \\
\text { ciente }\end{array}$ & Activo & Activo & Activo \\
\hline $\begin{array}{l}\text { Ontología del } \\
\text { deportista }\end{array}$ & Fracturada & Fracturada & Segura & Segura & $\begin{array}{l}\text { Fracturada y } \\
\text { segura }\end{array}$ \\
\hline
\end{tabular}

Tabla 2. Autoidentidad mediática de los deportistas paralímpicos colombianos 


\subsection{Autoidentidad Mediática Impuesta (AMI)}

Básicamente se trata de la valoración positiva que hicieron los entrevistados de noticias: A) que los presentaron -o donde ellos mismos se presentaroncomo modelos de inspiración, utilizando a su vez términos incorrectos como "a pesar de"; B) que incluyeron autorreferencias como "querer es poder" y "los límites están en la mente"; C) con titulares que los presentaron como "superhumanos" y "superhéroes"; D) que incorporaron discursos e imágenes gestionadas institucionalmente. Por ejemplo, el nadador Brayan Urbano considera que las y los atletas paralímpicas/os son modelos de inspiración "para muchos, inclusive para los jóvenes hoy en día que de pronto están en malos pasos, que están desenfocados de la vida, de pronto al mirarnos a nosotros les puede cambiar un poco más el pensamiento" (comunicación personal). Por su parte, el ciclista Javier Ayala está de acuerdo con que se les trate como superhumanos porque

nosotros hacemos más de lo que los humanos normales hacen, porque para nosotros no existen los límites, nosotros sobrepasamos nuestra discapacidad para salir adelante en un país como Colombia, donde lo miran como algo diferente y lo tratan como pobrecito ese man no sirve para nada.

Y la atleta Martha Lizcano aseguró que su poder es la valentía "así como la chica maravilla, que es fuerte, veloz, que no se deja derrumbar" (comunicación personal).

\subsection{Autoidentidad Mediática Asumida (AMA)}

En este caso, se observó la valoración positiva de las y los atletas paralímpicas / os a noticias que: A) resaltaron la condición deportiva de alto rendimiento como una consecuencia histórica y paralela a los Juegos Olímpicos, desde la normalización y el capacitismo; B) presentaron imágenes en primer plano con rostros sonrientes como estrategia de cercanía emocional con los héroes; C) utilizaron el relato épico como otro recurso de "anclaje de cercanía" en reportajes situados en un ámbito local; D) destacaron a las y los atletas paralímpicas/os más exitosos desde marcos supercrip.

Asimismo, en esta categoría se ubica la valoración negativa de las y los atletas paralímpicas/os a noticias: A) caracterizadas por contener información falsa o no verificada, invisibilizar (a los guías de atletismo) y términos 
incorrectos, incluidos los que usan entre ellos (verbigracia, cuando las/los atletas paralímpicas/os se refieren a otro como "el cieguito"); B) donde otros hablan por ellos (entrenadores, directivos); C) que los presentan desde un marco supercrip; D) que los retratan con fotografías inadecuadas. También en esta tipología fue valorado negativamente el poco interés institucional por la comunicación estratégica y la priorización de la cobertura institucional de los deportistas mejor proyectados. Todos estos casos, aunque valorados negativamente, fueron aceptados por los entrevistados, ya que de no ser así el deporte paralímpico sería invisibilizado, como ha sucedido en estudios similares (De Souza \& Brittain, 2020).

En este caso, la primera medallista paralímpica colombiana Martha Hernández confiesa, tras leer la inadecuada contextualización de su clasificación funcional: "uno hace algo por su país, pero los periodistas no investigan, no redactan bien la noticia [...] para uno salir en un artículo es lo máximo, pero que no lo sepan redactar es como una falta de respeto" (comunicación personal).

\subsection{Autoidentidad Mediática Negociada (AMN)}

En esta categoría aparece la valoración positiva basada en una postura crítica a noticias que: A) presentaron a las/los atletas paralímpicas/os como PCD y deportistas paralímpicos; B) resaltaron la condición deportiva de élite y alto rendimiento; C) los presentaron como héroes; D) amplían la información y ofrecen un panorama variopinto; E) recurren a la voz del/la atleta paralímpico/a para contextualizar fallas deportivas; F) hacen un reconocimiento desde el "nosotros"; G) son reflectores de su lucha política (medios independientes o alternativos especializados en paralimpismo).

A diferencia de la AMA, la valoración negativa de noticias con tratamiento inadecuado va acompañada de la intervención (rol activo) que las/los atletas paralímpicas/os hacen frente a este aspecto desde una postura progresista. Por ejemplo, cuando recordaron las veces que sintieron la necesidad de corregir a los periodistas y de reclamarles el rol social que tienen en la transformación de las narrativas sobre discapacidad. Por la misma línea, la AMN abarca la conciencia que tienen las/los atletas paralímpicas/os sobre su propio rol en la construcción de narrativas progresistas sobre discapacidad. Adicionalmente, se ubican en este tipo de autoidentidad quienes criticaron el tratamiento heroico, pero al mismo tiempo mostraron respeto por los deportistas que se sienten a gusto al ser presentados como héroes. 
Dos ejemplos a continuación: el ciclista Diego Dueñas, quien aseguró que si se llega achicopalado y mal vestido a la entrevista es muy probable que el periodista sienta lástima y quiera enfocarla desde el lado amarillista, como una experiencia que tuvo: "el periodista me dijo «Diego, hablemos de tu discapacidad». Yo lo miré a los ojos imponente y le dije «ino! lo importante son los logros». Entonces él paró la grabación y dijo «volvamos a empezar, cuéntame qué pasó» (comunicación personal). En esa línea también está el testimonio de la ciclista Daniela Munévar, quien exige respeto en los casos en que los periodistas se refieran a la discapacidad adquirida, tanto en la noticia como en una entrevista, pues afirma que "hay personas que les vale lo mismo y preguntan como si hubiera pasado cualquier cosa” (comunicación personal). Ambos casos demuestran la constante tensión que puede existir entre el modelo supercrip y el de pluralismo cultural en la cobertura del paralimpismo (Schell \& Rodríguez, 200I).

\subsection{Autoidentidad Mediática Rechazada (AMR)}

La AMR fue identificada en aquellos/as atletas paralímpicos/as proyectados como medallistas pero que no finalizaron su participación debido a una lesión, por lo que tuvieron escaso o nulo cubrimiento mediático. Esta situación los llevó a no consumir noticias sobre paralimpismo y a reconstruir su identidad pública desde otros lugares fuera de lo mediatizado. También en los deportistas que no reconocieron la diferencia entre medios de comunicación masivos y medios independientes especializados en paralimpismo, especialmente desde lo político. En general, estos sujetos valoraron negativamente el tratamiento inadecuado, calificándolo de discapacitante, desesperanzador e imposible de cambiar.

Un caso es el del maratonista y medallista paralímpico Elkin Serna, quien confiesa que ningún periodista colombiano se acercó para preguntarle qué sucedió tras el abandono de la carrera por lesión al iniciar la prueba, y continúa:

yo estaba muy triste y dije, hay que hablar y esclarecer, mucha gente quiere saber qué pasó con detalle y yo estaba preparado, en la prueba, luego en la Villa Olímpica, hasta intenté hacer un video y poner mi testimonio pero las cosas quedaron así (comunicación personal). 


\subsection{Autoidentidad No Mediática o Latente (ANMoL)}

Se encontraron casos en los que no existe autodefinición a partir de otros ni de ellos mismos en los medios, como el caso de la atleta Daniela Rodríguez, pero con una latente necesidad de reconocimiento público que los medios de comunicación podrían garantizar. Esta negación se dio debido a las fallas deportivas experimentadas por el/la atleta paralímpico/a o a la invisibilización de los guías de los atletas con discapacidad visual, quienes aseguraron que no les interesa ni les afecta no ser mencionados por los medios. En ambos casos, a partir de la ausencia mediática de su yo o la exposición de un yo no óptimo se da la negación de ser a través de los medios.

\section{Discusión}

El análisis textual permitió establecer que los periodistas colombianos respondieron a la tendencia derivada de Londres 20I2: hacer "intentos genuinos para comprender, informar y cubrir tales deportes y atletas que participan en los Juegos Paralímpicos más allá de los estereotipos y el lenguaje ofensivo y condescendiente" (Ellis \& Goggin, 2015: 73). Antes de esos juegos las noticias sobre el tema se producían de manera negativa, pasiva, medicalizada, orientadas a la discapacidad, individualizadas o centrándose en los Paralímpicos como deportes minoritarios, a pesar de que se organizan conjuntamente como un megaevento olímpico (Newlands, 20I2). Pero una característica que permaneció en la cobertura de Río en el caso colombiano analizado fue la tradicional, medicalizada, específicamente en el abordaje de las categorías de competencia de los deportistas y en los marcos de representación de "héroe discapacitado", supercrip o "inspiracional", teniendo en cuenta que por primera vez las y los atletas paralímpicas/os ocupaban un lugar en las primeras planas de los principales diarios del país.

Además, se evidenció una tendencia a incluir términos incorrectos y marcos inadecuados en la medida que la noticia era profundizada, es decir, si el atleta se destacó en su participación, el relato fue más allá de la información técnica sobre la competencia y los resultados, ofreciendo un contexto que podía incluir enfoques de tragedia, fragilidad y limitaciones, poniéndolos en una posición de 'pobre alma lamentable' en lugar de una de admiración por sus hazañas atléticas, como encontraron Hardin \& Hardin (2003). De otro lado, se identificó un tratamiento "normalizador" como el hallado en Solves (20I2), 
caracterizado por la falta de enfoque en la discapacidad, la contextualización de las categorías deportivas, y el agendamiento mediático del acontecimiento como tema de actualidad y deportivo, especialmente. Este aspecto normalizador al que se refiere Solves aborda un periodismo deportivo no diferenciable entre deporte convencional y paralímpico, que puede llevar a la eliminación de formas de discriminación.

Ya en diálogo con los deportistas, se encontró que, al igual que en el estudio de Huang (2005), incorporaron la discapacidad y el deporte a su sentido de identidad a través del yo paralímpico, en consecuencia, valoraron positivamente las imágenes que los muestran como deportistas de élite y personas en acción. En esa línea, se pudo establecer que en la medida en que los medios de comunicación los presentan como deportistas de alto rendimiento incrementan las posibilidades de que estos atletas desarrollen una autoidentidad mediática. De hecho, los entrevistados valoraron positivamente en mayor medida las noticias que se limitaron a ofrecer información sobre el desempeño deportivo y que los abordó médicamente solo en la mención de la categoría funcional de participación, ya que se limitaban a presentarlos a partir de su esencia: como deportistas paralímpicos. Como enfatizó la lanzadora Érica Castaño: "Considero que nosotros no somos protagonistas porque tengamos una discapacidad, somos protagonistas porque traemos resultados como cualquier otro deportista" (comunicación personal).

Este aspecto coincide con los estudios sobre el tema realizados hasta ahora: los deportistas con discapacidad se definen por sus logros y su competencia más que por sus discapacidades (Rojas-Torrijos \& Ramon, 202I), aun cuando en la denominación "paralímpico" persiste la etiqueta médica y la ideología capacitista. Asimismo, se enfrentan a la "paradoja paralímpica" de asumir dos roles sociales según Purdue \& Howe (20I2): un primer papel se construye principalmente para el público no discapacitado, en el que se muestra al atleta como de rendimiento deportivo y de élite que se esfuerza por conseguirlo "a pesar" de su diferencia física. El segundo rol, que es construido socialmente para la comunidad de PCD es el de enlace o mediador entre el deporte, el logro atlético y la diferencia física.

Específicamente sobre el abordaje de las categorías, que se hace desde un enfoque medicalizado dada la naturaleza de la clasificación funcional (sistema propio del deporte paralímpico para evaluar el impacto de la discapacidad en el rendimiento deportivo), se encontró que en su mayoría no son contextualizadas, por lo que vale la pena indagar si la ausencia de explicaciones se hace por falta de preparación del periodista, por omisión o mal abordaje del 
deportista entrevistado, o para mantener el estatus de "élite" de algunos atletas con discapacidad, como encontró Howe (2008).

Con respecto a los medios de comunicación, la más importante función asignada por las y los atletas paralímpicas/os es la de servir de plataforma para inspirar a otras personas con y sin discapacidad, en el sentido de promocionar el deporte como un proyecto de vida. Esto responde al discurso que el Comité Paralímpico Internacional promueve, por ejemplo, al premiar a los atletas por "un nivel excepcional de determinación para superar sus adversidades a través del deporte y los Juegos Paralímpicos". Por ejemplo, para Ellis y Goggin (20I5), este lente "inspirador" o "edificante" para el espíritu humano es condescendiente y extremadamente limitante.

En ese sentido, al validar las narrativas de superación, se acentúa lo ampliamente cuestionado por expertos en las últimas décadas: se propicia la formación de estándares irreales de comparación que pueden fomentar juicios desfavorables, especialmente sobre aquellas PCD que no son deportistas (Bartsch, Oliver, Nitsch \& Scherr, 20I8), pues estas narrativas supercrip no tienen en cuenta los factores sociales que experimentan las PCD y mantienen las lógicas de opresión sin llamar la atención a la eliminación definitiva de las formas de exclusión. Este aspecto fue tenido en cuenta por algunos atletas al incluir entre las funciones de los medios la de servir de reflectores ante reclamos de derechos y mejores condiciones laborales en el ejercicio del deporte, desde una perspectiva progresista.

Por esa vía, se constató que los atletas que desconocen el modelo progresista se caracterizaron por: a) no reconocer los términos incorrectos y valorarlos positivamente; $b$ ) adoptar y valorar positivamente los enfoques de tragedia y limitaciones, así como las narrativas de superación e inspiracionales; c) ignorar o restar importancia al papel de los medios en la construcción de imaginarios sociales positivos sobre discapacidad; $d$ ) no alentar prácticas adecuadas en la producción de noticias sobre discapacidad.

En contraste, se categorizaron como autoidentidades mediáticas negociadas (AMN) o rechazadas (AMR) aquellas que consciente e inconscientemente mostraron una perspectiva progresista manifestada en: a) el rechazo de las prácticas periodísticas que los afecta negativamente; $b$ ) la valoración negativa de noticias cuyo lenguaje y tratamiento es considerado inadecuado; c) la capacidad de reclamo frente a esta práctica; $d$ ) la necesidad de enseñar a los periodistas a transformarla. Sobre la base de lo anterior, en la medida que los DP conocen y adoptan un modelo progresista de autoconcepción y autoexperimentación de la discapacidad, se reduce el nivel de aceptación de imágenes 
y narrativas de cualquier tipo sobre sí mismos en los medios de comunicación a cambio de la exposición pública de cualquier tipo. En este punto los medios independientes especializados en paralimpismo también juegan un papel fundamental en la alfabetización mediática progresista (desde el submodelo de pluralismo cultural de Clogston (I990)), realizada tanto en la constante interacción con las y los atletas paralímpicas/os en eventos sobre paralimpismo como en el consumo que ellos hacen de sus contenidos (Meléndez-Labrador, 202I).

Finalmente, la indiferencia identificada en la Autoidentidad No Mediática se considera difusa ya que los DP al mismo tiempo valoraron positivamente las bondades que los medios de comunicación podían otorgarle a su imagen pública, por lo tanto, puede existir una autoidentificación mediática latente en la medida en que su yo pase de no considerarse un modelo de inspiración a uno que sí.

\section{Conclusiones}

Se concluye que, en la medida en que los medios digitales los muestran como atletas, especialmente que inspiran a otras personas con y sin discapacidad, incrementan las posibilidades de que estos deportistas desarrollen una autoidentidad mediática. En tal sentido, a partir de la valoración positiva o negativa de los elementos de la noticia, los deportistas se sintieron autoidentificados mediáticamente de manera impuesta, asumida, negociada o rechazada, o, por el contrario, manifestaron indiferencia con respecto a la imagen que de ellos presentaron los medios.

De igual manera, se constató que buena parte de las y los atletas paralímpicas/os carecen de conocimiento y adopción del modelo progresista de representación mediática de la discapacidad, por lo que valoran los discursos mediáticos supercrip con los que son representados como héroes o modelos de inspiración, no por sus logros deportivos, sino por su capacidad de superación "a pesar" de la discapacidad.

Asimismo, se observó una mayor tendencia a que los individuos ontológicamente fracturados valoraran positivamente los enfoques de tragedia y fragilidad presentes en las noticias estudiadas (AMI), o que los aceptaran a cambio de visibilidad (AMA), a diferencia de los individuos ontológicamente seguros que los cuestionaron y resignificaron (AMN) o rechazaron (AMR). Este aspecto es interesante abordarlo con mayor profundidad dado que, tanto en la 
presente investigación como en la de Pullen et al. (2020) se han encontrado manifestaciones de (auto)percepciones diferenciadas entre tipos de discapacidades y si es adquirida o congénita, que puede llevar a asumir una identidad frente al otro con algún tipo de jerarquía, aun dentro del sistema paralímpico. Ya lo aseguró el exatleta paralímpico Howe:

Casi todos los atletas y entrenadores que participan en el deporte paralímpico no reconocen la adversidad que lleva a la participación de los atletas. Los atletas que han nacido con una discapacidad congénita han conocido poca adversidad porque se han adaptado al mundo (2008: 143).

Adicionalmente, tras la revisión de la literatura se evidenció una nula investigación en el área realizada en o desde Hispanoamérica ${ }^{4}$, tras los primeros JJ. PP. en territorio latinoamericano (Río 20i6) y aun cuando México y Argentina figuran en el ranking de estas últimas justas. Asimismo, el presente estudio tiene en cuenta a atletas paralímpicos ciegos, cuyas experiencias poco se conocían (Jenks \& Jenks, 20I5). Entonces, se alienta a atender a Boyle cuando afirma que "el estudio de la comunicación y el deporte debe seguir diciéndonos verdades sobre los valores que tenemos como sociedad" (2012: 97). En otras palabras: el estudio de la comunicación del deporte paralímpico, junto con las avanzadas pesquisas realizadas desde Brasil sobre la materia, debe decirnos verdades sobre los valores que tenemos como sociedad en América Latina y el Caribe.

Para finalizar, es necesario resaltar que este tipo de eventos como los JJ. PP. facilitan la idea abordada por Goffman sobre que la persona estigmatizada “justifica la existencia de jerarquías interdiscapacidad discriminatorias, donde cada cuerpo posee su valor en función de su acercamiento o alejamiento al cuerpo capaz" (Ferrante, 2021: 26), por lo tanto, es necesario insistir en el interrogante sobre qué tan progresista puede ser un modelo de tratamiento mediático de la discapacidad en un escenario de estigmatización, segregación y exclusión como lo es el paralímpico. Sobre esa línea se destaca también que las guías sobre cubrimiento mediático del deporte para PCD tienen en cuenta solo aspectos del lenguaje escrito y verbal, las formas y medios de expresión y la interacción con los deportistas paralímpicos durante las entrevistas, mayormente desde una perspectiva medicalizada. Con esto, se recomienda reformular las guías o diseñar una nueva que tenga en cuenta una perspectiva de

\footnotetext{
${ }^{4}$ Salvo los dos trabajos de la autora.
} 
contextualización interseccional, por ejemplo, desde el Modelo de Accesibilidad Comunicativa Universal (Meléndez-Labrador, 2022), y que se base en las opiniones de los deportistas como las obtenidas en el presente estudio.

\section{Bibliografía}

Bartsch, A., Oliver, M. B., Nitsch, C., \& Scherr, S. 20I8. Inspired by the Paralympics: Effects of empathy on audience interest in para-sports and on the destigmatization of persons with disabilities. Communication Research 45(4): 525-553.

Boyle, R. 20I2. Reflections on communication and sport: On journalism and digital culture. Communication Q2 Sport I(I-2): 88-99.

Clogston, J. 1994. Disability Coverage in American Newspapers. En Nelson, Jack (ed.) The Disabled, the Media and the Information Age. Westport: Greenwood Press, 45-57.

Cheong, J. P. G., Khoo, S., Inoue, C., Surujlal, J., Cheong, N., Esfahani, M., Lin, P.H., Brooke, M., Li, Y., Chun, H., Alshahrany, A., Al-Shamli, A., \& Razman, R. 2020. An II-country analysis of newspaper coverage of the 2016 Rio Paralympic Games. Disability ax Society: I-I7.

De Souza, D. \& Brittain, I. 2020. The Rio 2016 Paralympic Games: The visibility of people with disabilities in Brazil as a possible legacy. Communication and Sport. doi: Io.II77/2167479520942739

EFDS. 20I6. Media Guide: Reporting on disabled people in sport. English Federation of Disability Sport.

Ellis, K., \& Goggin, G. 20I5. Disability and the Media. London: Palgrave Macmillan.

Ferrante, C. 202I. Rising Phoenix y la filosofía del "deporte para discapacitados" de Ludwig Guttmann ¿Un legado para romper prejuicios? Lecturas: Educación Física y Deportes 26(275).

Figueiredo, T. H., \& Novais, R. A. 20I0. A visão bipolar do pódio: olímpicos versus paraolímpicos na mídia on-line do Brasil e de Portugal. Logos 17(2): 78-89.

Giddens, A. 1996. Modernidad y autoidentidad. En Beriain, J. (comp.) Las consecuencias perversas de la modernidad: modernidad, contingencia y riesgo. Barcelona: Anthropos, 33-72.

Haller, B. I995. Rethinking models of media representations of disability. Disability Studies Quarterly 15(2): 26-30.

Haller, B. 2000. If They limp, They Lead: News Representations and the Hierarchy of Disability Images. En Braithwaite, D. \& Thompson, T. (ed.) Handbook of Communication and People with Disabilities: Research and Application. New Jersey/ London: Lawrence Erlbaum Associates, 273-88.

Hardin, B., \& Hardin, M. 2003. Conformity and conflict: Wheelchair athletes discuss sport media. Adapted Physical Activity Quarterly 20(3): 246-259. doi: I0.II23/ apaq.20.3.246 
Howe, P. D. 2008. From Inside the Newsroom: Paralympic Media and the "Production" of Elite Disability. International Review for the Sociology of Sport (43)2: I35-I5O.

Huang, C. J. 2005. Discourses of disability sport: Experiences of elite male and female athletes in Britain and Taiwan (Tesis Doctoral). United Kingdom: Brunel University.

IPC. 20I4. Guide to reporting on persons with an impairment. International Paralympic Committee.

Jenks, E. B., \& Jenks, A. B. 2or4. An inside look at an invisible Paralympic sport: Giving voice to goalball athletes' lived experiences. En Reframing Disability? Media, (Dis) Empowerment, and Voice in the 2012 Paralympics. Routledge, 234-248

Kolotouchkina, O., Llorente-Barroso, C., García-Guardia, M. L., \& Pavón, J. 2021. Disability, Sport, and Television: Media Visibility and Representation of Paralympic Games in News Programs. Sustainability 13(I), 256.

Kühne, R., \& Schemer, C. 20I5. The Emotional Effects of News Frames on Information Processing and Opinion Formation. Communication Research 42(3): 387 407. doi: Io.II77/0093650213514599

Lindemann, K., \& Cherney, J. L. 2008. Communicating In and Through "Murderball": Masculinity and Disability in Wheelchair Rugby. Western Journal of Communication 72(2): 107-I25. doi: 10.1080/10570310802038382

Meléndez-Labrador, S. 202I. Periodismo alternativo, alfabetización y co-construcción del imaginario social de la discapacidad en los juegos de Río 20I6. Chasqui. Revista Latinoamericana de Comunicación 1(I46): I4I-I58.

Meléndez-Labrador, S. (2022). El lugar de la lengua de señas como lengua minoritaria en la Accesibilidad Comunicativa Universal. Anuario Electrónico de Estudios en Comunicación Social “Disertaciones” I5(I): I-2I. doi: IO.I2804/revistas.urosario .edu.co/disertaciones/a.IoI27

McGillivray, D., O’Donnell, H., McPherson, G., \& Misener, L. 202I. Repurposing the (Super)Crip: Media Representations of Disability at the Rio 2016 Paralympic Games. Communication \& Sport 9(I): 3-32. doi: 10.II77/2167479519853496

Newlands, M. 20I2. Debunking Disability. Media Discourse and the Paralympic Games. En Schantz, O. \& Gilbert, K. (ed.) Heroes or Zeros? The Media's Perception of Paralympic Sport. Campaign, Il.: Common Ground, 209-224.

Organización de las Naciones Unidas (ONU). 2006. Convención sobre los derechos de las personas con discapacidad. https://www.un.org/spanish/disabilities/default. asp? id $=497$

Pavlenko, A., \& Blackledge, A. 2004. Introduction: New Theoretical Approaches to the Study of Negotiation of Identities in Multilingual Contexts. Multilingual Matters, I-33.

Pappous, A. \& Souza, D. 20I6. Media Guide: How to cover the Rio 2016 Paralympic Games. En Media Guide: How to cover the Rio 2016 Paralympic Games. United Kingdom: University of Kent. 
Purdue, D. E., \& Howe, P. D. 20I2. See the sport, not the disability: exploring the Paralympic paradox. Qualitative research in sport, exercise and health 4(2): I89205 .

Pullen, E., Jackson, D., Silk, M., Howe, P. D., \& Silva, C. F. 2020. Extraordinary Normalcy, Ableist Rehabilitation, and Sporting Ablenationalism: The cultural (re-) production of Paralympic disability narratives. Sociology of Sport Journal, 38(3): 209-2I7.

Rojas-Torrijos, J. \& Ramon, X. 202I. Exploring Agenda Diversity in European Public Service Media Sports Desks: A Comparative Study of Underrepresented Disciplines, Sportswomen and Disabled Athletes' Coverage on Twitter. Journalism Studies 22(2): 225-242. doi: 10.1080/1461670X.2020.1809497

Schell, B., \& Rodriguez, S. 200I. Subverting bodies/ambivalent representations: Media analysis of Paralympian, Hope Lewellen. Sociology of Sport Journal I8: ı27I35.

Solves Almela, J. 20ıо. El discurso sobre la discapacidad en los medios como objeto de estudio. En Comunicación y desarrollo en la era digital: actas del II Congreso AE-IC. Málaga.

Solves, J. (coord.). 2012. Tratamiento de los Juegos Paralímpicos de 2008 en los medios españoles. Madrid: Cermi.

Solves, J., Sánchez, S., \& Rius, I. 20I8. The prince and the pauper: Journalistic culture and Paralympic games in the Spanish print press. Journalism I9(I2): I7I3-I729. doi: https://doi.org/Io.II77/I464884916671894

Uribe-Jongbloed, E., \& Sarmiento, M. F. P. 20I4. Negociaciones de identidad en la radio indígena y étnica colombiana: tres casos de estudio. Anagramas: Rumbos y sentidos de la comunicación 13(25): 167-I88. 